\title{
Adult grisel's syndrome: report of a rare case
}

\begin{abstract}
Grisel's Syndrome consists of an atlantoaxial subluxation due to laxity associated with ligament inflammation, usually after infectious processes of the head and neck. It is an extremely rare disease in adults and it's diagnosis implies a high level of suspicion. Because of its rarity, adult treatment is not completely established. The authors aim to present the case of a 27-year-old patient surgically treated with atlantoaxial arthrodesis by the Wright technique, with a good result at 5 years of follow-up.
\end{abstract}

Keywords: grisel syndrome, atlanto-axial instability, atlanto-axial arthrodesis
Volume 5 Issue I - 2020

\author{
Alfredo Carvalho, André Pinho, Francisco \\ Serdoura,Vitorino Veludo \\ Orthopedics Service, Centro Hospitalar, São João, Portugal
}

Correspondence: Alfredo Carvalho, Orthopedics Service, Centro Hospitalar, São João, Portugal,Tel: 964124106 Email alfredoemcarvalh@gmail.com

Received: December 13, 2019 | Published: January 06, 2019

\section{Introduction}

Grisel's syndrome is an atlanto-axial instability resulting from ligament laxity caused by inflammation due to head and neck infections, and was described in 1930 by a French Otorhinolaryngologist. ${ }^{1}$ It is a typical condition of pediatric patients, with only 14 cases described in adult age. ${ }^{2}$ The main symptom is neck pain, which can be associated with cervical instability, and neurological symptoms due to spinal cord or root compression, which can ultimately lead to the death. ${ }^{2}$ The functional status of the patient can be followed with the Neck Disability Index (NDI), wich is a modification of the Oswestry Low Back Pain Disability Index, a patient-completed, condition-specific functional status questionnaire with 10 items including pain, personal care, lifting, reading, headaches, concentration, work, driving, sleeping and recreation. ${ }^{3}$

Imaging studies show an increase in Atlanto-Dens Interval (ADI), with an increase in this distance on dynamic radiographs showing atlantoaxial instability, as well as inflammatory changes in perivertebral soft tissues on magnetic resonance imaging. ${ }^{4}$

Contrary to pediatric cases, where conservative treatment is usually effective, $\mathrm{C} 1-\mathrm{C} 2$ surgical stabilization may be necessary in adulthood, although the paucity of cases described in this age group does not aloud strong recommendations. ${ }^{5}$

The authors present a case of adult Grisel's Syndrome, surgically treated with posterior atlanto-axial arthrodesis, using the Wright technique, which consists of atlanto-axial fixation using $\mathrm{C} 1$ lateral mass screws, connected with rods to $\mathrm{C} 2$ trans-laminar screws ${ }^{6}$ with good clinical and imaging results at 3 years of follow-up.

\section{Clinical case}

A 27-year-old male patient with no relevant medical or surgical history and working in the military army, was observed in an Orthopedics consultation, referred from primary health care for complaints of neck pain, without irradiation to the upper limbs, associated with limitation of mobility, especially in sagittal plane movements, with 4 months of evolution (Neck Disability Index (NDI) of 26). The patient denied a history of trauma, but reported upper respiratory infection (pharyngitis) one month before the onset of cervical pain. Physical examination revealed decreased cervical mobility, without other major findings. The diagnostic study began with two-plane cervical radiography (Figure 1), with an approximate ADI value of $10.5 \mathrm{~mm}$, as well as dynamic radiographs (Figure 2), which demonstrated C1-C2 dynamic instability (ADI of 10.9 and $9.8 \mathrm{~mm}$ respectively). The CT study confirmed atlanto-axial sub dislocation and excluded the presence of fractures or facet subluxations (Figure 3 ). The study was complemented by magnetic resonance imaging, which confirmed atlanto-axial sub dislocation, associated with inflammation and thickening of the paravertebral soft tissues, with transverse ligament incompetence (Figure 4 - magnetic resonance imaging). Due to the decreased mobility of the upper cervical spine, the possibility of Meningitis was raised. Blood analytical study showed marginal elevation of C-Reactive Protein $(28 \mathrm{mg} / \mathrm{L})$, thus, the hypothesis of Grisel's Syndrome was placed. The patient was initially treated with the use of a Minerva cervical collar and broad-spectrum empirical antibiotic therapy with Ceftriaxone for 6 weeks, but after this period, there was unfavorable clinical evolution, with worsening of cervical pain and functional status (NDI of 30). Surgical treatment was therefore elected, through posterior atlanto-axial fixation, which is in accordance with other cases published in the literature. ${ }^{2}$ The surgery was uneventful and the patient had a favorable clinical course, with significant improvement in neck pain and joint mobility, with an improvement in the NDI from 30 to 5. Radio graphically, a reduction in atlanto-axial subluxation was confirmed (Figure 5), which remained stable until 5 years of follow-up. There were no late complications and the patient resumed his normal activities.

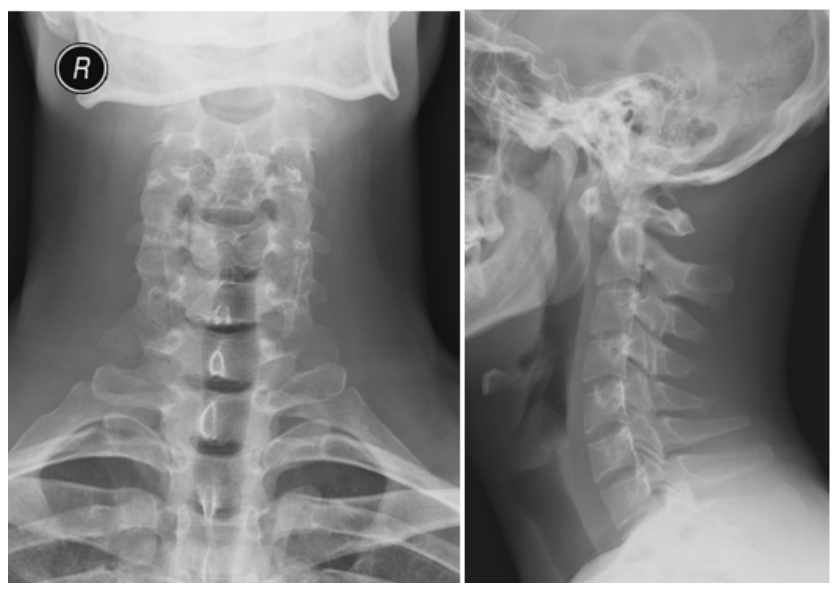

Figure I Initial radiografic study. 

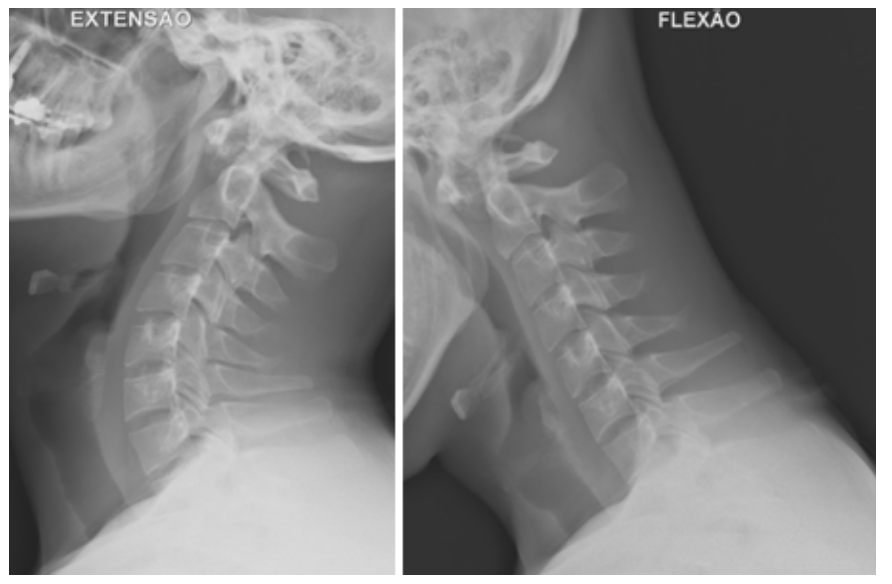

Figure 2 Dynamic study with $\mathrm{Cl}-\mathrm{C} 2$ instability.

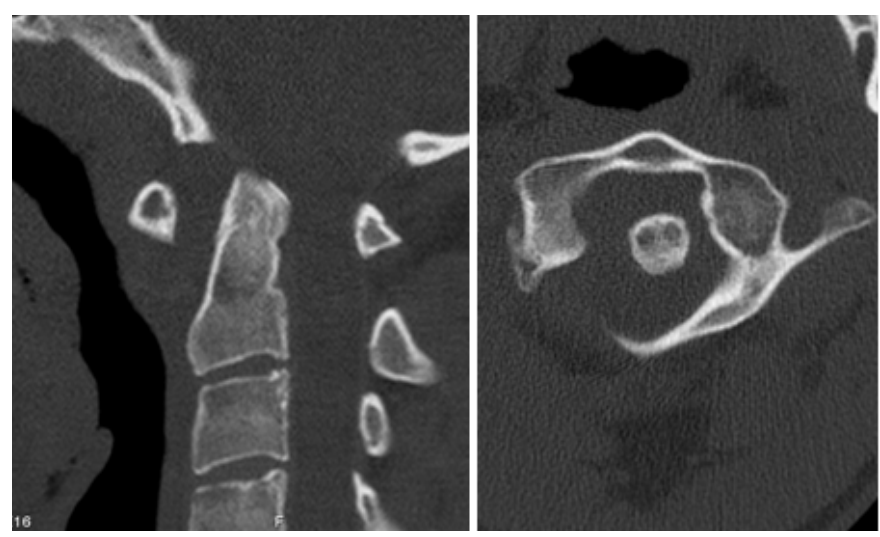

Figure 3 TC image with $\mathrm{Cl}-\mathrm{C} 2$ dislocation.

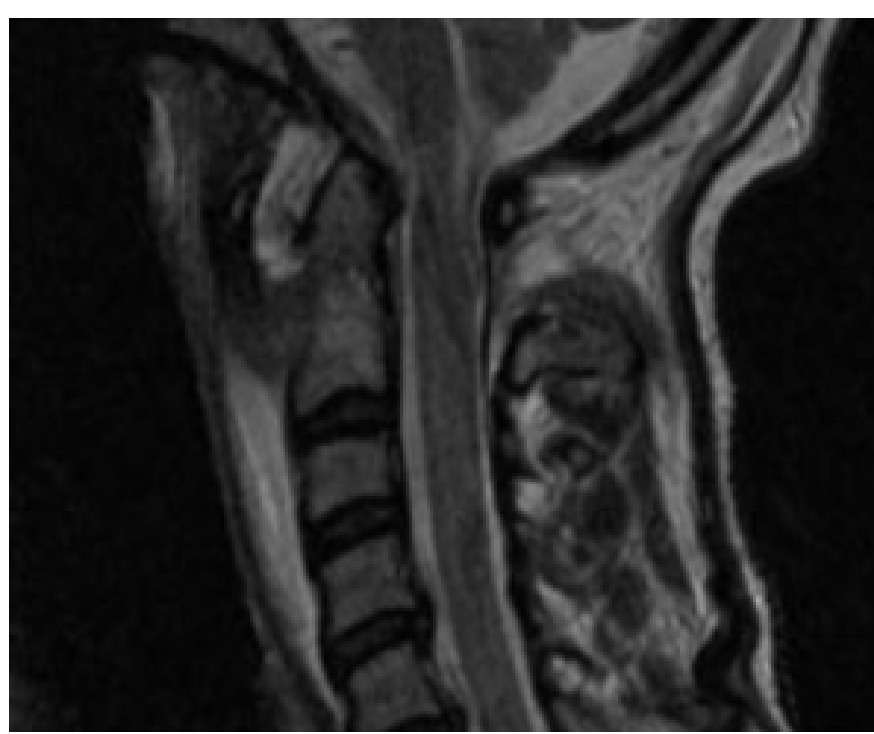

Figure 4 Magnetic Ressonance image showing $\mathrm{Cl}-\mathrm{C} 2$ inflamatory tissue.

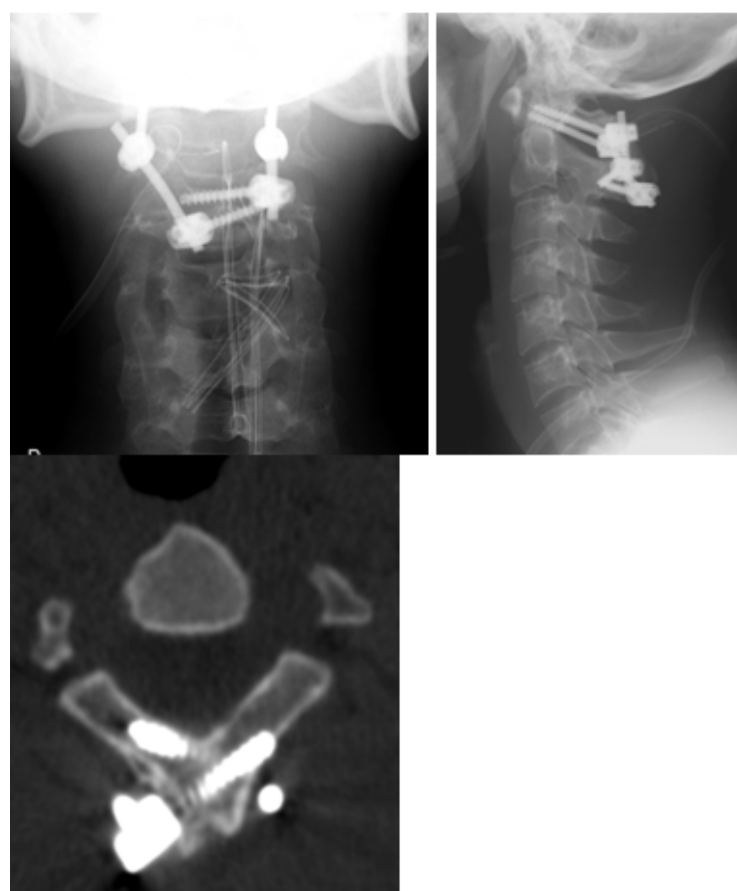

Figure 5 Radiografic result 5 years after surgery.

\section{Discussion and conclusion}

Grisel's syndrome is a typical pediatric entity described in the early twentieth century, and since then only 14 cases in adulthood have been described, which attests to the rarity of the case. ${ }^{2}$ This disease may result from different types of head and neck infections, such as pharyngitis, tonsillitis, otitis, among others, or as a complication of diagnostic or surgical procedures, with biopsy and tonsillectomies. ${ }^{7}$ Diagnosis is often hampered by the mismatch between infection and cervical symptoms and the absence of findings in the diagnostic tests at an early stage, so this is a diagnosis of exclusion. ${ }^{8}$ The pathophysiology of Grisel Syndrome is not completely established, and there are different theories: response to muscle spasm due to inflammation; decalcification of the anterior arch of the atlas resulting from vascular hyperemia caused by the infectious process; previous atlantoaxial laxity aggravated by inflammatory mediators that reach the zone through the pharyngovertebral plexus. ${ }^{9}$

At pediatric age there is usually a positive response to conservative treatment with immobilization and antibiotic therapy. However, treatment in adults often requires surgery, as conservative treatment is associated with bad clinical results. ${ }^{2}$

There are a number of atlanto-axial surgical stabilization techniques, such as Brooks sub-laminar wiring, Magerl trans-articular screw, and Harms $\mathrm{C} 1$ lateral mass - $\mathrm{C} 2$ pedicle screw technique. The technique described by Wright in 2004 is technically simpler and with a lower risk of vascular or nerve injury compared to the previous ones, presenting overlapping biomechanical resistance. ${ }^{6,10,11}$

In conclusion, adult Grisel's Syndrome is an extremely rare entity whose diagnosis may be delayed by the time lapse between 
the infectious event and the cervical symptoms. In this age group, surgical treatment is often required, but there is a lack of large sample studies to make strong recommendations regarding treatment in the adult subset of patients.

\section{Acknowledgements}

None.

\section{Conflicts of interest}

The authors declare no conflicts of interest.

\section{References}

1. Grisel P. Enucleation de l'atlas et torticollis nasopharyngien. Press Med. 1930;38:50.

2. Mena K, Jean E, Fontes R, et al. Atlantoaxial instability of inflamatory origin in adults: case reports, literature review and rationale for early surgical intervention. Neurossurgery. 2015;76:E226 - E232.

3. Macdermid JC, Walton DM, Avery S, et al. Measurement properties of the neck disability index a sustematic review. Journal of Orthopedic and Sports Physical Therapy. 2009;39(5):400-417.

4. Harth M, Meyer M, Marzi I, et al. Lateral torticollis on plain radiographs and MRI: grisel syndrome. Eur Radiol. 2004;14(9): 1713-1715.
5. Allegrini D, Autelitano A, Nourino E, et al. Grisel's syndrome, a rare cause of anamalous head posture in children: a case report. BMC Opth. 2016;16:21

6. Wright NM. Posterior $\mathrm{C} 2$ fixation using bilateral, crossing $\mathrm{C} 2$ laminar screws: case series and technical note. $J$ Spinal Dis Tech. 2004;17(2):158-162

7. Spennato P, Nicosia G, Rapaná A, et al. Grisel syndrome following adenoidectomy: surgical management in a case with delayed diagnosis. World Neurosurg. 2015;84(5):1494.

8. Yu K, White D, Weissler M, et al. Nontraumatic atlantoaxial subluxation (grisel syndrome): a rare complication of otolaryngological procedures. Laryngoscope. 2003;113(6):1047-1049.

9. Watson-Jones R, Roberts PE. Calcification, decalcification and ossification. Br J Surg. 1934;21:461-499.

10. Bellil M, Hadhri K, Sridi M, et al. Traumatic atlantoaxial rotatory fixation associated with $\mathrm{C} 2$ articular facet fracture in adult patient: case report. $J$ Craniovertebr Junction Spine. 2015;5:163-166.

11. Aurich L, Milano J, Junior E, et al. C2 translaminar screw fixation (Wright's technique). applicability in atlantoaxial instability. J Bras Neurosurg. 2012;23(2):152-156. 